\title{
Relações interdimensionais e produtividade de pinhão-manso (Jatropha curcas L.) em sistema silvipastoril
}

\author{
Interdimensional relations and yield of jatropha \\ (Jatropha curcas L.) in silvopastoral system
}

\author{
Rubens Fey ${ }^{1 *}$; Ubirajara Contro Malavasi²; Marlene Matos Malavasi²; \\ Deisinara Giane Schulz ${ }^{3}$; João Alexandre Lopes Dranski ${ }^{4}$
}

\section{Resumo}

A morfometria de um vegetal com suas variáveis são utilizadas para inferir sobre relações interdimensionais, e sua análise é importante para obter informações da sua estabilidade, vitalidade e produtividade. O objetivo deste trabalho foi determinar as variáveis morfométricas, as relações interdimensionais e a produtividade de pinhão manso cultivado em sistema silvipastoril. Foram mensuradas 45 árvores aos três anos após o plantio em Latossolo no Oeste do Paraná. As características analisadas foram: diâmetro do caule, altura, diâmetro da copa, comprimento da copa, área da copa, proporção da copa, grau de esbeltez, índice de saliência, índice de abrangência, formal da copa, número de ramos e a produtividade. As avaliações foram realizadas entre janeiro de 2011 e julho de 2011 . O diâmetro do caule foi a variável que melhor se correlacionou com o a produtividade da cultura do pinhão-manso. Para essa variável, também foram obtidos modelos de regressão significativos para: altura da planta, diâmetro da copa, grau de esbeltez e índice de abrangência.

Palavras-chave: Morfometria, produção, estimativa

\begin{abstract}
Plant morphometric variables are used to estimate interdimensional relations, and their analysis is important to obtain information on the plant's stability, vitality, and yield. The aim of this study was to determine the morphometric variables, interdimensional relations, and the yield of jatropha grown in a silvopastoral system. Forty-five trees were measured for three years following cultivation in Latossolo, West Paraná. The characteristics under analysis were as follows: stem diameter, height, crown diameter, crown length, crown area, crown proportion, slenderness ratio, salience index, coverage index, crown formation, number of branches, and yield. The assessments were carried out between January 2011 and July 2011. Stem diameter showed the best correlation with jatropha crop yield. For the same variable, significant regression models were obtained for the following: plant height, crown diameter, slenderness ratio, and coverage index.
\end{abstract}

Key words: Morphometry, production, estimate

\footnotetext{
${ }^{1}$ Prof. Dr. da Universidade Federal da Fronteira Sul, UFFS, Laranjeiras do Sul, PR. E-mail: rubens.fey@uffs.edu.br

2 Profs. Drs. do Programa de Pós Graduação em Agronomia/PPGA da Universidade Estadual do Oeste do Paraná, UNIOESTE, Marechal Cândido Rondon, PR. E-mail: biramalavasi@yahoo.com.br; marlenemalavasi@yahoo.com.br

${ }^{3}$ Discente do Programa de Pós Graduação em Agronomia/PPGA, UNIOESTE, Marechal Cândido Rondon, PR. E-mail: deisi_gs@ hotmail.com

${ }^{4}$ Pesquisador do Programa de Pós Doutorado, UNIOESTE, Marechal Cândido Rondon, PR. E-mail: joaodranski@yahoo.com.br

* Autor para correspondência
} 


\section{Introdução}

O pinhão manso (Jatropha curcas L.), pertencente à família euforbiaceae, é uma planta originária da América Central (FAIRLESS, 2007) e possivelmente do Brasil (CARVALHO et al., 2008). A espécie tem tido importância econômica pelo potencial uso na fabricação de biodiesel, fator importante em meio às crises de petróleo e da pressão para utilizar energias menos poluentes. Devido a este potencial, muitos recursos foram alocados visando à produção e industrialização de óleo de pinhão manso. No entanto, trabalhos científicos sobre essa planta para ainda são reduzidos.

Estudos morfométricos estáticos e dinâmicos em vegetais lenhosos são de fundamental interesse para direcionar e adequar práticas silviculturais, tais como controle do espaçamento, poda e colheita (ROMAN; BRESSAN; DURLO, 2009). Avaliar diretamente todos os dados biométricos das árvores a campo torna-se inviável. Portanto, a avaliação indireta via determinação de uma variável de fácil obtenção, que tenha dependência com a variável de interesse, tornase necessária (TOMÉ, RIBEIRO; FAIAS, 2007). As relações morfométricas interdimensionais têm sido utilizadas para descrever o comportamento tanto em florestas nativas (DURLO; DENARDI, 1998; NUTTO, 2001; TONINI; ARCO-VERDE, 2005; ROMAN; BRESSAN; DURLO, 2009), quanto em exóticas (NUTTO et al., 2001) para potencializar a produção de madeira.

Ainda não existem descrições publicadas do uso das relações interdimensionais em pinhão manso. $\mathrm{O}$ objetivo deste trabalho foi determinar as variáveis morfométricas, as relações interdimensionais e a produtividade de pinhão manso em sistema silvipastoril.

\section{Material e Métodos}

O experimento foi conduzido na área experimental localizada a 24039"43'S e 54¹5"53'W, município de Pato Bragado, Paraná, Brasil. O clima da região, segundo classificação de Köppen é o subtropical úmido mesotérmico (Cfa) com verões quentes (temperatura média superior a $22{ }^{\circ} \mathrm{C}$ ) e invernos com geadas pouco frequentes (temperatura média inferior a $18^{\circ} \mathrm{C}$ ). A precipitação média anual no período experimental foi de 1949,56 mm (figura 1). O local do experimento é considerado apto pelo zoneamento agroclimático para o cultivo do pinhão manso (ANDRADE et al., 2007).

Este experimento trabalhou com plantas provenientes de sementes. Estas sementes foram obtidas de um cultivo comercial localizada em Pedro Juan Caballero - Paraguai. Naquele local, as matrizes também foram obtidas por sementes colhidas de uma seleção de árvores encontradas há muitos anos naquela região.

Com as sementes foram produzidas as mudas em tubetes de $120 \mathrm{~cm}^{3}$ com substrato comercial PLANTMAX HA ${ }^{\circledR}$ em ambiente protegido. Foi empregada fertilização de base, adicionando-se 4 $\mathrm{kg} \mathrm{m}^{-3}$ da formulação N-P-K (10-10-10) e adubação de cobertura, composta por $200 \mathrm{~g}$ de $\mathrm{N}$ e $150 \mathrm{~g} \mathrm{~K}_{2} \mathrm{O}$ $\mathrm{m}^{-3}$, parcelada quinzenalmente após a emergência das plantas (GONÇALVES et al., 2005).

O plantio a campo ocorreu em dezembro de 2007 , a partir de mudas com tamanho homogêneo, em espaçamento de $3 \times 2 \mathrm{~m}$ perfazendo uma população de 1666 plantas ha-1. A área do experimento de $1440 \mathrm{~m}^{2}$ contabilizou 240 mudas em 4 linhas de 60 plantas cada.

O solo do experimento foi classificado como Latossolo Vermelho distroférrico argiloso (EMBRAPA, 2006). Antes do plantio, a análise do solo revelou as seguintes características químicas: 2,95 e 1,43 $\mathrm{mg} \mathrm{dm}^{-3}$ de P (extrator Mehlich-1); 30,07 e 23,24 $\mathrm{g} \mathrm{dm}^{-3}$ de matéria orgânica; $\mathrm{pH}$ em $\mathrm{CaCl}_{2}\left(0,01 \mathrm{~mol} \mathrm{~L}^{-1}\right)$ de 5,65 e 4,64; 6,38 e 4,28 cmolc dm-3 de $\mathrm{H}+\mathrm{Al}, 0$ e $0,3 \mathrm{cmol}_{\mathrm{c}} \mathrm{dm}^{-3}$ de $\mathrm{Al}$; 0,36 e $0,08 \mathrm{cmol}_{\mathrm{c}} \mathrm{dm}^{-3}$ de K; 3,09 e $2,52 \mathrm{cmol}_{\mathrm{c}} \mathrm{dm}^{-3}$ de Ca; 1,28 e 1,07 $\mathrm{cmol}_{\mathrm{c}} \mathrm{dm}^{-3} \mathrm{de} \mathrm{Mg} ; 11,60$ e 13,00 $\mathrm{mg} \mathrm{dm}{ }^{-3}$ de $\mathrm{Cu} 5,65$ e 4,64; 66,00 e 63,00 $\mathrm{mg} \mathrm{dm}^{-3}$ de $\mathrm{Mn} ; 3,5$ e 2,10 $\mathrm{mg} \mathrm{dm}^{-3}$ de $\mathrm{Zn} ; 33,40$ e $36,80 \mathrm{mg}$ 
$\mathrm{dm}^{-3}$, respectivamente, nas camadas de 0 a 20 e de 21 a $40 \mathrm{~cm}$ de profundidade. A saturação por bases foi de 42 e $46 \%$ nas camadas de 0 a $20 \mathrm{~cm}$ e de 21 a $40 \mathrm{~cm}$ de profundidade.

O controle de plantas daninhas no primeiro ano foi realizado através do coroamento das plantas a cada três meses. Após esse período a área foi ocupada pela herbácea Tifton- 85 proveniente da área circunvizinha.
Todo experimento foi implantado e conduzido sem irrigação, correção de acidez, adubação e podas. As práticas culturais realizadas a partir do segundo ano de implantação incluíram a aplicação de inseticidas, para controle de Pachycoris torridus (Scopoli) e ácaros, e de fungicidas para o controle de oídios presentes com alta frequência na área experimental.

Figura 1. Distribuição das chuvas durante o período de dezembro de 2007 a julho de 2011 na área experimental. Dados Instituto das Águas, 2011.

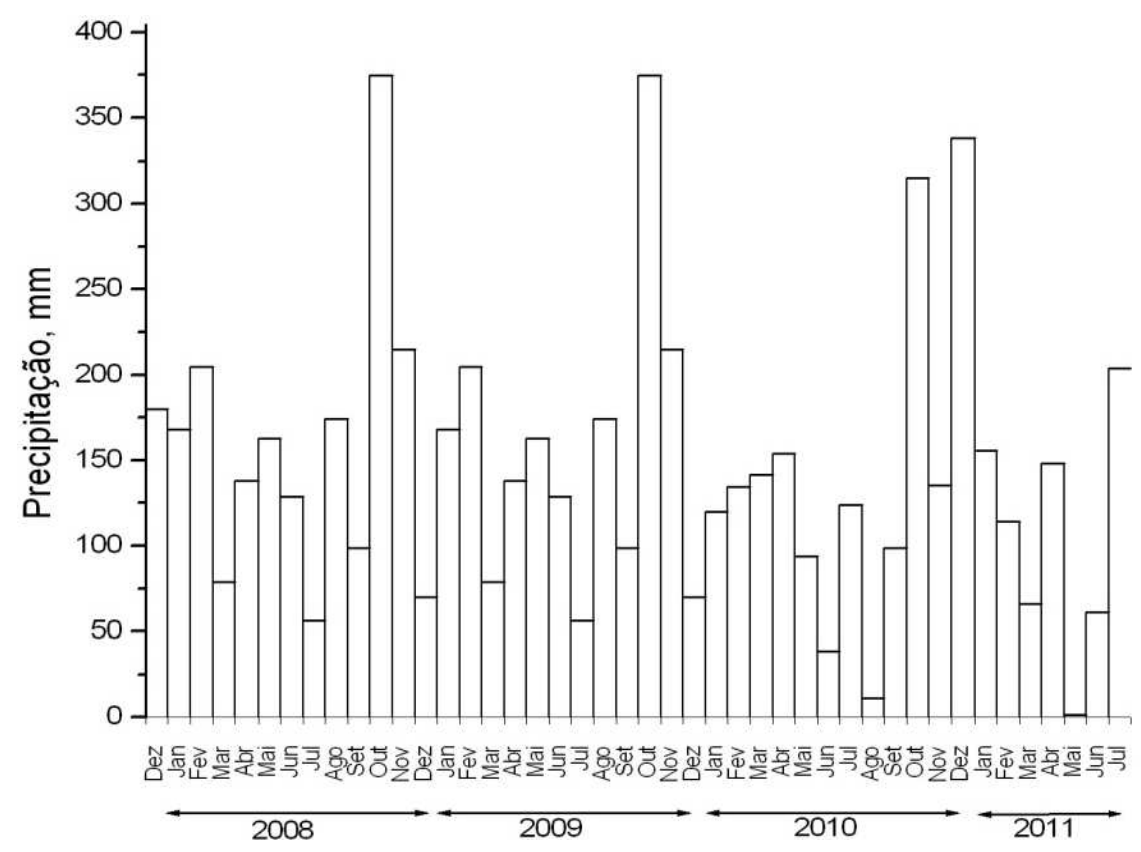

Fonte: Elaboração dos autores.

A avaliação das variáveis morfométricas e da produtividade foi realizada aleatoriamente em delineamento inteiramente casualizado (DIC) em 45 plantas localizadas nas duas linhas centrais do experimento, descartando as 2 plantas no início de cada linha, também descartando as que visualmente eram resultantes de replantio em janeiro e junho de 2011. As variáveis morfométricas avaliadas incluíram o diâmetro do caule a $5 \mathrm{~cm}$ do solo (dc), a altura total (h), o diâmetro da copa (dcop) resultante de duas medidas tomadas no sentido norte-sul e leste-oeste, o comprimento de copa (cc) resultante da distância vertical entre a folha mais próxima e a mais distante do solo, e o número de ramos maiores que $5 \mathrm{~cm}$ de comprimento. Com as variáveis acima descritas foram calculadas as seguintes relações: área de projeção da copa $\left(\mathrm{ac}=\mathrm{dcop}^{2} * \pi / 4\right)$, proporção da copa $(\mathrm{pc}=\mathrm{cc} / \mathrm{h} * 100)$, grau de esbeltez ( $\mathrm{ge}=\mathrm{h} / \mathrm{dc}$ ), índice de saliência (is $=\mathrm{dcop} / \mathrm{dc}$ ), índice de abrangência $(\mathrm{ia}=\mathrm{dcop} / \mathrm{h}$ ), e formal da copa ( $\mathrm{fc}$ $=\mathrm{dcop} / \mathrm{cc}$ ) conforme (DURLO; DENARDI, 2009). 
O frutos foram colhidos nos estágios 4 (5 Y 8/8), 5 (7 YR 4/2) e 6 (5 YR 3/2) de maturação fisiológica das sementes (DRANSKI et al., 2010) em onze colheitas de janeiro a julho de 2011. Após cada colheita, os frutos foram secos a $60{ }^{\circ} \mathrm{C}$ até atingir o peso constante em estufa de circulação forçada. Todas as sementes colhidas foram pesadas em balança de precisão (0,0001 g). As amostras de sementes foram secas a $105{ }^{\circ} \mathrm{C}$ por $24 \mathrm{~h}$ para obtenção do peso seco e correção da umidade para $13 \%$. Os resultados foram transformados para $\mathrm{kg}$ ha-1 multiplicando a produtividade de g planta-1 pelo fator 1,6 (1666/1000), de acordo com o espaçamento da área experimental que foi de $3 \times 2$ $\mathrm{m}\left(6 \mathrm{~m}^{2} /\right.$ planta $)$.

A seleção dos modelos foi realizada com o programa SAEG 9.0 (Sistema para Análises Estatísticas) pelo procedimento de modelos predefinidos I e o programa SPSS 11.5 (Statistical Package for the Social Sciences) com o procedimento stepwise. O aceite de cada modelo levou em consideração o maior valor de $\mathrm{R}^{2}$, menor erro padrão da estimativa (Syx), teste F significativo, e avaliação de resíduos (não tendenciosidade e normalidade de distribuição dos erros da estimativa).

\section{Resultados e Discussão}

\section{Características morfométricas}

Os valores médios, máximos e mínimos da morfometria das plantas de pinhão manso, após 3 anos do plantio (Tabela 1) evidenciam uma variação no diâmetro do caule de 6,0 a 16,2 cm. Esta variação pode ser considerada alta, já que todas as plantas receberam o mesmo tratamento. A propagação via semente é possivelmente a principal causa. $\mathrm{O}$ pinhão manso possui uma alta variabilidade entre plantas (Tabela 1), conforme relatos de diversos autores (ARRUDA et al., 2004; BELTRÃO et al., 2006). Esta variabilidade pode ser contornada com o plantio de mudas provenientes de um mesmo clone (LIMA et al., 2010).

Tabela 1. Características morfométricas para pinhão manso pesquisado.

\begin{tabular}{lccccc}
\hline Variável & min & média & max & des,pad & CV\% \\
\hline Diâmetro do caule [dc] (cm) & 6,60 & 10,35 & 16,20 & 2,28 & 22,01 \\
Altura [h] (m) & 1,58 & 2,07 & 2,75 & 0,30 & 14,27 \\
Diâmetro da copa [dcop] (m) & 0,80 & 1,73 & 2,95 & 0,53 & 30,56 \\
Comprimento da copa [cc] (m) & 0,80 & 1,39 & 2,05 & 0,32 & 23,40 \\
Área de copa [ac = dcop2 * $\pi / 4](\mathrm{m} 2)$ & 0,53 & 2,58 & 6,83 & 1,52 & 58,96 \\
Proporção da copa [cc/h*100] $(\%)$ & 48,0 & 66,0 & 85,0 & 7,00 & 11,14 \\
Grau de esbeltez [h/dc] & 13,89 & 20,50 & 26,52 & 2,93 & 14,28 \\
Índice de Saliência [dcop/dc] & 12,12 & 16,51 & 22,22 & 2,40 & 14,55 \\
Índice de Abrangência [dcop/h] & 0,46 & 0,83 & 1,23 & 0,18 & 22,25 \\
Formal de copa [dcop/cc] & 0,67 & 1,25 & 1,86 & 0,27 & 21,68 \\
\hline
\end{tabular}

Fonte: Elaboração dos autores.

A altura total apresentou a menor variação com $\mathrm{CV}=14,27 \%$ (Tabela 1) com valor médio de 2,07 m e desvio padrão de $30 \mathrm{~cm}$. Em cultivos florestais, a altura é uma característica representativa para avaliação de sítios florestais (SELLE; SCHNEIDE; FINGER, 1994). Porém, para pinhão manso, a altura é limitante para o manejo da colheita, seja manual ou mecânica (ARRUDA et al., 2004). A poda pode ser utilizada para auxiliar no controle da altura que pode chegar a 12 metros em indivíduos isolados adultas (SANTOS et al., 2011).

O diâmetro de copa de $1,73 \mathrm{~m}$ indica que o espaçamento entre plantas utilizado ainda é adequado para a média das plantas. Porém, o crescimento em largura é mais desejado que em altura, por facilitar a colheita, e como as plantas 
ainda estão com apenas três anos, espera-se que este diâmetro aumente, podendo ocasionar a competição intraespecífica por luminosidade (TONINI; ARCOVERDE, 2005).

A área de copa média foi de $2,58 \mathrm{~m}^{2}$ ou quase $50 \%$ da área útil de crescimento. Este valor de cobertura pode prejudicar a colonização e o crescimento de espécies do sub-bosque (SOARES et al., 2009). Porém, a alta variabilidade atrelada a esta variável $(\mathrm{CV}=58,56 \%)$ não permitiu nenhuma redução visual no crescimento mesmo nas plantas com área de copa de $6,83 \mathrm{~m}^{2}$.

A proporção da copa $(\mathrm{cc} / \mathrm{h} * 100)$ foi superior a 65\% (Tabela 1), considerada alta em comparação a espécies arbóreas cujo objetivo é a produção de madeira (ROMAN; BRESSAN; DURLO, 2009). Essa formação de ramos e folhas próximo ao solo é considerada favorável pelos fatores relacionados à facilidade de colheita. Porém, ao analisar o formal de copa (dcop/cc) pode-se constatar que o índice está próximo a $1(1,25)$ e confere a característica arredondada. Um volume muito grande de copa, associado ao formato arredondado pode proporcionar um microclima favorável ao desenvolvimento de fungos e insetos pela menor circulação de ar, e menor insolação no interior da copa. Técnicas de poda podem reduzir esses efeitos (BRITO, 2008).

O grau de esbeltez $(\mathrm{h} / \mathrm{dc})$ expressa a estabilidade da árvore. Plantas com este índice muito alto demonstram desproporcionalidade entre a altura e o diâmetro do caule, e possivelmente encontrase em competição e suprimidas por dominantes adjacentes (ROMAN; BRESSAN; DURLO, 2009). Nas plantas de pinhão manso analisadas, o índice variou de 13,89 a 26,52 com média de 20,5, valor considerado baixo em comparação aos de plantas arbóreas nativas (DURLO; DENARDI, 1998; TONINI; ARCO-VERDE, 2005).

O índice de saliência (is) médio calculado foi de 16,51 (Tabela 1). Em árvores com a finalidade de produção de madeira, este índice é utilizado para o controle do espaçamento a fim de reduzir a competição (ROMAN; BRESSAN; DURLO, 2009). Em sistema silvipastoril, valores altos deste índice podem representar maior disponibilidade de sombra aos animais. Porém, ainda não existem parâmetros na literatura para discutir com este foco.

$O$ índice de abrangência (ia) calculado fica prejudicado pelo fato de que a altura é considerada fator limitante na colheita dos frutos, e consequentemente tende a ser controlada por poda resultando em pouca importância para o manejo da cultura.

\section{Relações interdimensionais}

As análises de regressão de cada variável, considerando-se como variável independente o diâmetro de caule $(\mathrm{dc})$ baseou-se na facilidade de mensuração (Tabela 2) e por apresentar correlação significativa a $1 \%$ de probabilidade com as demais variáveis (Tabela 3 ).

Todas as variáveis externaram ajuste de regressão significativo em relação ao dc. Porém, a proporção da copa, o índice de saliência, e o formal da copa resultaram em ajuste do $\mathrm{R}^{2}$ abaixo de $30 \%$ o que pode resultar em erros ao considerá-los dependentes do de (ROMAN; BRESSAN; DURLO, 2009). Estes autores também não encontraram dependência destas mesmas relações como DAP em Cordia trichotoma.

A altura das plantas pode ser estimada pela equação da Tabela 2, com um Syx (\%) menor que 10\%. A importância desta estimativa para pinhão manso é menor que em árvores para a produção de madeira já que na cultura do pinhão manso não é desejável altura superior ao alcance do trabalhador que realiza a colheita, e porque a altura possui baixa correlação direta com a produção de grãos para óleo (TOMÉ; RIBEIRO; FAIAS, 2007). 
Tabela 2. Modelos de regressão para as variáveis morfométricas de pinhão manso.

\begin{tabular}{lllll}
\hline Variável & Modelo & $\mathrm{R} 2$ & Sign & Syx $(\%)$ \\
Altura [h] & $\mathrm{h}=0,174+(0,272 * \mathrm{dc})-\left(0,00817 * \mathrm{dc}^{2}\right)$ & 0,594 & $<0,001$ & 9,32 \\
Diâmetro da copa [dcop] & $\ln \mathrm{dcop}=-2,496+(1,296 * \ln \mathrm{dc})$ & 0,835 & $<0,001$ & $12,65 *$ \\
Comprimento da copa [cc] & $\mathrm{cc}=-0,384+(0,247 * \mathrm{dc})-\left(0,00696 * \mathrm{dc}^{2}\right)$ & 0,491 & $<0,001$ & 17,05 \\
Área de copa [ac = dcop2 $* \pi / 4]$ & $\mathrm{l} \_\mathrm{ac}=-5,197+\left(2,578 * \ln \_\mathrm{dc}\right)$ & 0,837 & $<0,001$ & $24,30^{*}$ \\
Proporção da copa [cc/h*100] & $\mathrm{cc} / \mathrm{h} * 100=50,046+(1,575 * \mathrm{dc})$ & 0,236 & $<0,001$ & 9,90 \\
Grau de esbeltez [h/dc] & $\mathrm{h} / \mathrm{dc}=44,466-(10,358 * \ln \mathrm{dc})$ & 0,620 & $<0,001$ & 8,91 \\
Índice de Saliência [dcop/dc] & $\mathrm{dcop} / \mathrm{dc}=0,698+(2,639 * \mathrm{dc})-\left(0,102 * \mathrm{dc}^{2}\right)$ & 0,247 & 0,003 & 12,92 \\
Índice de Abrangência [dcop/h] & $\mathrm{dcop} / \mathrm{h}=-0,662+\left(0,643 * \ln \_\mathrm{dc}\right)$ & 0,607 & $<0,001$ & 13,97 \\
Formal de copa [dcop/cc] & $\mathrm{dcop} / \mathrm{cc}=-0,260+\left(0,653 * \ln \_\mathrm{dc}\right)$ & 0,287 & $<0,001$ & 18,56 \\
\hline
\end{tabular}

*Valor do erro com base em "m", utilizando-se a retransformação da soma dos quadrados dos resíduos.

Fonte: Elaboração dos autores.

Tabela 3. Matriz de correlação entre as variáveis morfométricas, relações interdimensionais e a produtividade de pinhão manso.

\begin{tabular}{|c|c|c|c|c|c|c|c|c|c|c|c|}
\hline \multirow{2}{*}{ Variável } & \multicolumn{11}{|c|}{ Coeficientes de correlação (Pearson) } \\
\hline & $\mathrm{dc}$ & $\mathrm{h}$ & dcop & $\mathrm{cc}$ & $\mathrm{ac}$ & $\mathrm{pc}$ & ge & is & ia & $\mathrm{fc}$ & $\mathrm{nr}$ \\
\hline $\mathrm{h}$ & $0,75^{* *}$ & - & - & - & - & - & - & - & - & - & - \\
\hline dcop & $0,89 * *$ & $0,76^{* *}$ & - & - & - & - & - & - & - & - & - \\
\hline $\mathrm{cc}$ & $0,69 * *$ & $0,94 * *$ & $0,73 * *$ & - & - & - & - & - & - & - & - \\
\hline $\mathrm{ac}$ & $0,87 * *$ & $0,75^{* *}$ & $0,99 * *$ & $0,72 * *$ & - & - & - & - & - & - & - \\
\hline $\mathrm{pc}$ & $0,48 * *$ & $0,70 * *$ & $0,54 * *$ & $0,89 * *$ & $0,54 * *$ & - & - & - & - & - & - \\
\hline ge & $-0,78^{* *}$ & $-0,21 \mathrm{~ns}$ & $-0,64 * *$ & $-0,16 \mathrm{~ns}$ & $-0,59 * *$ & $-0,06 \mathrm{~ns}$ & - & - & - & - & - \\
\hline is & $0,43 * *$ & $0,49 * *$ & $0,78^{* *}$ & $0,50 * *$ & $0,77 * *$ & $0,39 * *$ & $-0,24 \mathrm{~ns}$ & - & - & - & - \\
\hline ia & $0,77 * *$ & $0,42 * *$ & $0,90 * *$ & $0,40 * *$ & $0,88 * *$ & $0,29 \mathrm{~ns}$ & $-0,78^{* *}$ & $0,77 * *$ & - & - & - \\
\hline $\mathrm{fc}$ & $0,52 * *$ & $0,06 \mathrm{~ns}$ & $0,63 * *$ & $-0,06 \mathrm{~ns}$ & $0,60 * *$ & $-0,22 \mathrm{~ns}$ & $-0,76^{* *}$ & $0,58 * *$ & $0,87 * *$ & - & - \\
\hline $\mathrm{nr}$ & $0,85^{* *}$ & $0,80 * *$ & $0,89 * *$ & $0,78 * *$ & $0,90 * *$ & $0,60 * *$ & $-0,52 * *$ & $0,60 * *$ & $0,71 * *$ & $0,41 * *$ & - \\
\hline prod & $0,84 * *$ & $0,72 * *$ & $0,78 * *$ & $0,67 * *$ & $0,81 * *$ & $0,50 * *$ & $-0,53 * *$ & $0,39 * *$ & $0,60 * *$ & $0,34^{*}$ & $0,86^{* *}$ \\
\hline
\end{tabular}

$\mathrm{h}=$ altura; dcop = diâmetro de copa; $\mathrm{cc}=$ comprimento de copa; $\mathrm{ac}=$ área de copa; $\mathrm{pc}=$ proporção de copa; ge = grau de esbeltez; is = índice de saliência; ia = índice de abrangência; $\mathrm{fc}=$ formal de copa; $\mathrm{nr}=$ número de ramos; prod = produtividade. $* *$ Correlação significativa ao nível de $1 \%$. * Correlação siganificativa ao nível de 5\%. ns Correlação não siganificativa

Fonte: Elaboração dos autores.

O logaritmo do diâmetro de copa possui ajuste crescente com o logaritmo do diâmetro de caule. $\mathrm{O}$ diâmetro de copa indica o espaço necessário para que as plantas possam se desenvolver sem que haja competição entre elas. Diâmetro de copa superior ao espaçamento utilizado pode indicar a necessidade de desbaste de algumas plantas ou podas de parte dos ramos. No entanto, o desbaste não é prática comum em áreas de pinhão manso, enquanto as pesquisas do efeito da poda sobre a produtividade ainda são limitadas (BRITO, 2008; OLIVEIRA; BELTRÃO, 2010).
O comprimento da copa (cc) é uma medida importante em pinhão manso, considerando que a altura tende a ser limitada. O modelo quadrático representou sua dependência com o diâmetro do caule, e teve maior comprimento estimado a $17,74 \mathrm{~cm}$ de dc. Estudos são ainda necessários para demonstrar o efeito do cc na produtividade de frutos, pois neste ensaio apesar da correlação total de 0,78 significativa a $1 \%$ (Tabela 3 ), o efeito direto desta variável sobre a produtividade foi de apenas 0,04 (Tabela 4). 
Tabela 4. Estimativa dos efeitos diretos e indiretos dos coeficients de trilha sobre a produção de sementes de pinhão manso em sistema silvipastoril.

\begin{tabular}{|c|c|c|c|c|}
\hline \multirow[b]{2}{*}{ Variáveis } & \multirow[b]{2}{*}{ Vias de associação } & \multicolumn{2}{|c|}{ Coeficientes de Trilha } & \multirow[b]{2}{*}{$\begin{array}{l}\text { Coeficiente } \\
\text { de correlação }\end{array}$} \\
\hline & & Efeito direto & Efeito indireto & \\
\hline \multirow[t]{6}{*}{ dc } & Efeito direto sobre dc/prod & 0,5041 & & \\
\hline & Efeito indireto via $\mathrm{h}$ & & $-0,015$ & \\
\hline & Efeito indireto via dcop & & $-0,230$ & \\
\hline & Efeito indireto via cc & & 0,0295 & \\
\hline & Efeito indireto via $\mathrm{nr}$ & & 0,5496 & \\
\hline & Total (direto e indireto) & & & 0,8370 \\
\hline \multirow[t]{6}{*}{$\mathrm{h}$} & Efeito direto sobre h/prod & $-0,0209$ & & \\
\hline & Efeito indireto via dc & & 0,3797 & \\
\hline & Efeito indireto via dcop & & $-0,197$ & \\
\hline & Efeito indireto via cc & & 0,0404 & \\
\hline & Efeito indireto via $\mathrm{nr}$ & & 0,5196 & \\
\hline & Total (direto e indireto) & & & 0,7216 \\
\hline \multirow[t]{6}{*}{ dcop } & Efeito direto sobre dcop/prod & $-0,2579$ & & \\
\hline & Efeito indireto via dc & & 0,4503 & \\
\hline & Efeito indireto via $h$ & & $-0,016$ & \\
\hline & Efeito indireto via cc & & 0,0312 & \\
\hline & Efeito indireto via nr & & 0,5766 & \\
\hline & Total (direto e indireto) & & & 0,7842 \\
\hline \multirow[t]{6}{*}{$\mathrm{cc}$} & Efeito direto sobre cc/prod & 0,0429 & & \\
\hline & Efeito indireto via dc & & 0,3474 & \\
\hline & Efeito indireto via $\mathrm{h}$ & & $-0,019$ & \\
\hline & Efeito indireto via dcop & & $-0,187$ & \\
\hline & Efeito indireto via nr & & 0,5030 & \\
\hline & Total (direto e indireto) & & & 0,6857 \\
\hline \multirow[t]{6}{*}{$\mathrm{nr}$} & Efeito direto sobre $\mathrm{nr} / \mathrm{prod}$ & 0,6452 & & \\
\hline & Efeito indireto via dc & & 0,4293 & \\
\hline & Efeito indireto via $\mathrm{h}$ & & $-0,016$ & \\
\hline & Efeito indireto via dcop & & $-0,230$ & \\
\hline & Efeito indireto via cc & & 0,0334 & \\
\hline & Total (direto e indireto) & & & 0,8607 \\
\hline
\end{tabular}

$\mathrm{dc}=$ diametro de caule; $\mathrm{h}=$ altura; $\mathrm{dcop}=$ diâmetro de copa; $\mathrm{cc}=$ comprimento de copa; $\mathrm{nr}=$ número de ramos .

Fonte: Elaboração dos autores.

A área de copa apresentou o melhor ajuste de $\mathrm{R}^{2}$, porém a equação ajustada detém um erro padrão de 24,30\% em relação à média. Esta extensa variação também pode ser observada na Tabela 1 , pois esta variável apresentou o maior desvio padrão proporcional a sua escala de medida. Portanto, esta equação também possui restrições quanto a sua utilização.

A relação h/dap (grau de esbeltez) demonstrou que plantas de pinhão manso tendem a priorizar o engrossamento do caule (Tabela 2). Tendências semelhantes também foram reportadas por outros autores com árvores nativas. A escala deste índice em pinhão manso é menor que árvores nativas. Roman, Bressan e Durlo (2009) com louro-pardo obtiveram uma escala de 130 a 47,8 enquanto Durlo e Denardi (1998) calcularam índices entre 29,8 a 173. Neste ensaio, este índice variou de 26,89 a 13,89 (Tabela 1). Ao observar as tabelas 1 e 3 , nota-se que a altura variou menos que o diâmetro do 
caule, e que é o dc que possui correlação negativa significativa com o grau de esbeltez, diferente da altura (não significativo).

O índice de abrangência (is) aumentou com o aumento da dc. Ao aumentar o dc, o pinhão manso aumenta o diâmetro de copa em maior proporção que em altura. Este índice pode servir de indicador de população de plantas por hectare por sua relação com a produtividade (Tabela 2). Porém, neste ensaio não foi possível determinar uma equação válida para ajustar a produtividade, em função dos critérios pré-estabelecidos.
Colheita e produtividade de pinhão manso em sistema silvipastoril

A colheita ocorreu entre 10 de janeiro e 07 de julho de 2011, totalizando 6 meses (Figura 2). Foram necessárias 11 colheitas para que todos os frutos pudessem ser recolhidos sem perdas. Este extenso período de colheita pode ser limitante em função de sua viabilidade econômica (não avaliada neste estudo), principalmente nas datas que foram colhidas menos de $5 \%$ do total (Figura 2). A maior parte da produção experimental $(85 \%)$ foi colhida em 01 e 06 de janeiro, 31 de maio, e 15 de julho.

Figura 2. Distribuição da produção ao longos de 6 meses, em proporção do total (a) e produtividade média em função da frequencia de colheita (b). Barras idicam erro padrão.

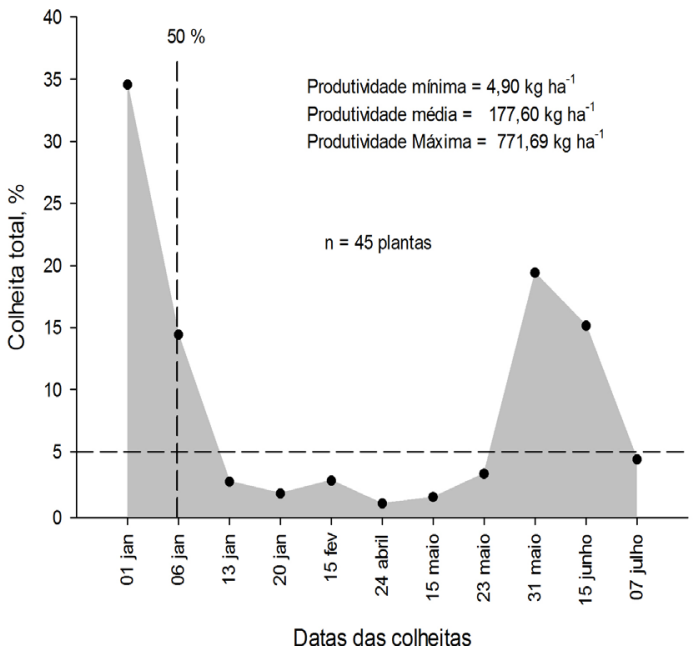

Datas das colheitas

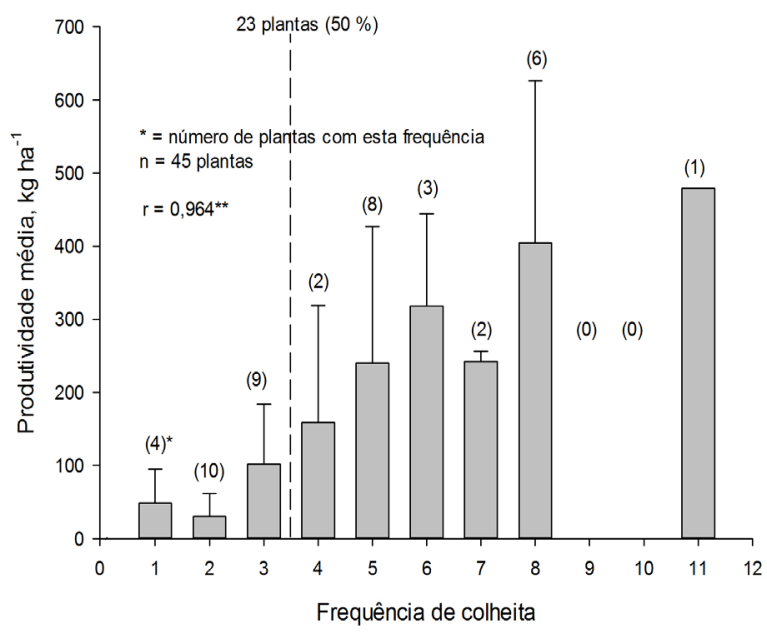

Fonte: Elaboração dos autores.

Metade da produção foi colhida na primeira semana e em $50 \%$ das plantas foram necessárias até 3 frequências de colheita (Figura 2). Plantas com menor frequência de colheita produziram menos, com ajuste de correlação de Pearson entre produtividade média com frequência de colheita de 0,964 , significativo a $1 \%$. Mas este resultado deve ser utilizado com cautela devido ao alto erro padrão (Figura 2).

A produtividade mínima foi de $4,90 \mathrm{~kg} \mathrm{ha}^{-1}$ e a máxima de $771,69 \mathrm{~kg} \mathrm{ha}^{-1}$ com média de $177,60 \mathrm{~kg}$ ha $^{-1}$ nas 45 plantas avaliadas. Estes valores são muito inferiores aos relatados em eventos para divulgação da cultura como de Carnielli (2003), porém muito próximos a pesquisa de Abou Kheira e Atta (2009) que trabalharam com diferentes lâminas de irrigação em pinhão manso. Estes autores obtiveram produções médias entre 90,42 a 195,08 kg ha-1 nos diferentes tratamentos num período de colheita de 75 dias. Neste ensaio a água não foi fator limitante a produtividade (Figura 1).

O solo utilizado no experimento pode ter 
limitado a produtividade geral do experimento. Esta observação é diferente da descrita por Arruda et al. (2004) que descreveram o pinhão manso como uma planta com baixa exigência nutricional. A concentração de fósforo foi baixa na superfície $(0$ $-20 \mathrm{~cm})$ e muito baixa na sub-superfície $(21-40$ $\mathrm{cm}$ ) enquanto a saturação com os nutrientes $\mathrm{Mg}$, Ca e K na CTC (capacidade de troca de cátions) também foi classificada como baixa segundo Ribeiro, Guimarães e Alvarez V. (1999). Segundo aquele autor, nestes níveis é necessária a correção e adubação do solo para implantação de mudas no campo. No entanto, para pinhão manso ainda existem níveis críticos determinados pela pesquisa.

A competição por nutrientes pela pastagem também pode ter limitado a produtividade. A Tifton 85 é considerada altamente extratora de nutrientes (MATOS et al., 2010). Porém, parte destes nutrientes extraídos pela pastagem era devolvida ao solo pelo processo de mineralização, pois sua matéria seca não era exportada. Além desta competição, Laviola e Dias (2008) observaram que o pinhão manso extrai elevada quantidade de nutrientes pela exportação dos frutos, e caso estes não sejam adequadamente repostos via adubação, pode reduzir a capacidade do solo em fornecer nutrientes.

Todas as variáveis morfométricas e relações interdimensionais tiveram correlação significativa com a produtividade (Tabela 3). No entanto, a proporção da copa, grau de esbeltez, índice de saliência e o formal de copa resultaram em coeficientes inferiores a 55\% mostrando-se pouco associados. A associação da área de copa foi desconsiderada por ser resultado do diâmetro da $\operatorname{copa}(\mathrm{ac}=\mathrm{dcop} 2 * \pi / 4)$. As variáveis com correlação superior a $70 \%$ foram o diâmetro de copa, a altura, o comprimento de copa, e o número de ramos.

No entanto, as correlações da Tabela 3 (correlação de Pearson) consideram a soma dos efeitos diretos e indiretos das variáveis morfométricas sobre a produtividade. $\mathrm{Na}$ decomposição dos efeitos apenas o diâmetro do caule e o número de ramos causando um efeito direto superior a $50 \%$ sobre a produtividade (Tabela 4). As demais correlações de altura, diâmetro de copa e comprimento de copa são influenciadas por efeitos indiretos do diâmetro de caule e número de ramos. A explicação para a associação da produtividade com o número de ramos é muito simples, pois a floração ocorre na extremidade dos ramos (LUCENA et al., 2010).

A relação do diâmetro do caule e do número de ramos é expressa pela Equação 1.

Produtividade $\left(\mathrm{kg} \mathrm{ha}^{-1}\right)=-288,51+(30,304 * \mathrm{dc})+$ $(4,272 * \mathrm{nr})$

Equação 1

$$
\mathrm{R}^{2}=0,78
$$

Sendo: $\mathrm{dc}=$ diâmetro do caule, $\mathrm{cm}$; $\mathrm{nr}=$ número de ramos.

A produtividade de pinhão manso aumenta com o crescimento em diâmetro e com novos ramos (Equação 1). A proporção desse aumento, para cada unidade de ganho, é maior do diâmetro do caule em relação ao número de ramos.

A quantificação do número de ramos de pinhão manso é difícil a campo e sujeita a erros em função do grande número de ramos por planta (Tabela 1), mas pode ser estimada pela Equação 2.

$\operatorname{ln\_ nr}=-3,117+\left(2,800 * \ln \_d c\right) \quad$ Equação 2 $\mathrm{R}^{2}=0,82$

Sendo: $\ln \_n r=$ logaritmo do número de ramos; Ln_ $\mathrm{dc}=$ logaritmo do diâmetro de caule.

Na Figura 3 pode-se observar a relação isolada do diâmetro do caule e do número de ramos sobre a produtividade. Apesar da redução do coeficiente de determinação em comparação a Equação 1, os modelos obtiveram ajustes ainda superiores a $70 \%$. A produtividade em função do número de ramos é mais bem explicada pelo modelo linear, 
enquanto o quadrático ajustou-se melhor para sua dependência com o diâmetro do caule. Para ambos não foi possível encontrar a produtividade máxima.
O erro padrão da estimativa da produtividade foi menor ao ser determinado pelo diâmetro de caule. O diâmetro do caule é uma medida de fácil obtenção e de baixo erro.

Figura 3. Produtividade de sementes de pinhão manso em função do número de ramos e do diâmetro de caule.

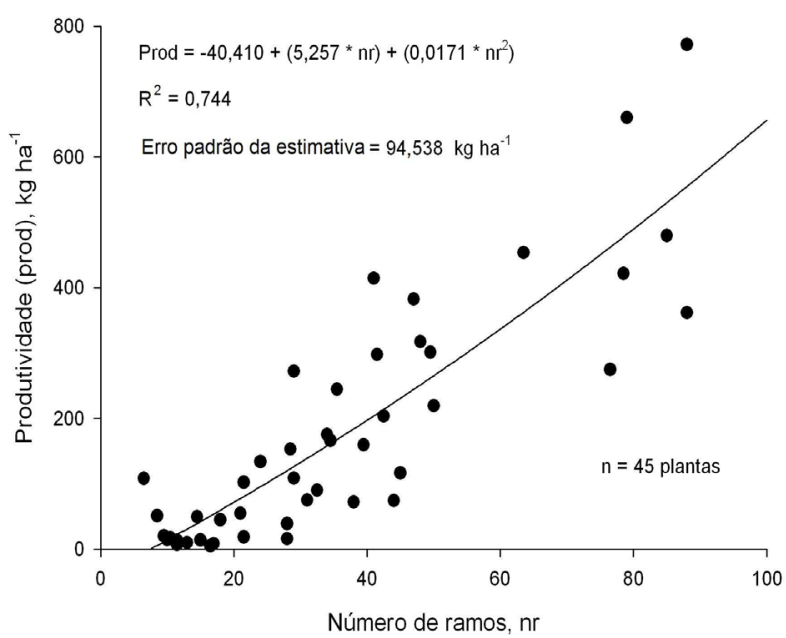

Fonte: Elaboração dos autores.

\section{Conclusões}

O pinhão manso possui grande variação na sua morfometria e produtividade.

O diâmetro do caule é a variável de fácil obtenção que melhor se correlaciona com o a produtividade da cultura do pinhão-manso. Esta variável também pode ser usada para estimar a altura, diâmetro de copa, área de copa, grau de esbeltez, índice de abrangência e número de ramos do pinhão-manso.

\section{Agradecimentos}

A Capes pelo financiamento desta pesquisa e pela concessão de bolsa PNPD (programa nacional de pós doutorado) ao primeiro autor.

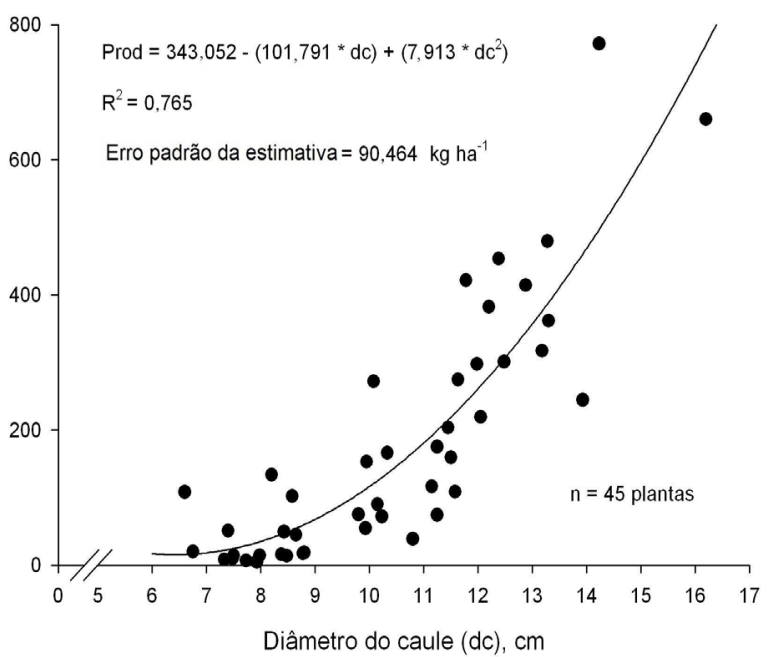

\section{Referências}

ABOU KHEIRA, A. A.; ATTA, N. M. M. Response of Jatropha curcas L. to water deficits: yield, water use efficiency and oilseed characteristics. Biomass and Bioenergy, Elsevier, v. 33, n. 10, p. 1343-1350, 2009.

ANDRADE, G. A.; CARAMORI, P. H.; CAVIGLIONE, J. H.; OLIVEIRA, D.; RIBEIRO, A. M. A. Zoneamento agroclimático para a cultura do pinhão-manso (Jatropha curcas L.) no Estado do Paraná. Revista Brasileira de Agrometeorologia, Piracicaba, v. 15, n. 2, p. 178-183, 2007.

ARRUDA, F. P. D.; BELTRÃO, N. E. M.; ANDRADE, A. P.; PEREIRA, W. E.; SEVERINO, L. S. Cultivo de Pinhão-manso (Jatropha curcas L.) como alternativa para o semiárido nordestino. Revista Brasileira de Oleaginosas e Fibrosas, Campina Grande, v. 8, n. 1, p. 789-799, 2004. 
BELTRÃO, N. E. D. M.; SEVERINO, L. S.; VELOSO, J. F.; JUNQUEIRA, N.; FIDELIS, M.; GONÇALVES, N. P.; SATURNINO, H. M.; ROSCOE, R.; GAZZONI, D. DUARTE, O. J.; DRUMOND, M. A.; ANJOS, J. B. Alerta sobre o plantio de pinhão-manso no Brasil. Campina Grande: Embrapa Algodão, 2006. 15 p. (Embrapa Algodão. Documento, 155).

BRITO, J. F. Efeito da poda no desenvolvimento de pinhão manso (Jatropha curcas L.) nas condições de Gurupi Tocantins. 2008. Dissertação (Mestrado em Agronomia) -Universidade Federal de Tocantins, Guripi.

CARNIELLI, F. O combustível do futuro. Belo Horizonte: UFMG, 2003. 4 p. (UFMG, Boletim, 1413).

CARVALHO, C. R.; CLARINDO, W. R.; PRAÇA, M. M.; ARAÚJO, F. S.; CARELS, N. Genome size, base composition and karyotype of Jatropha curcas L., an important biofuel plant. Plant Science, Elsevier, v. 174, n. 6, p. 613-617, 2008.

DRANSKI, J. A. L.; PINTO JÚNIOR, A. S.; STEINER, F.; ZOZ, T.; MALAVASI, U. C.; MALAVASI, M. M.; GUIMARÃES, V. F. Physiological maturity of seeds and colorimetry of fruits of Jatropha curcas L. Revista Brasileira de Sementes, Londrina, v. 32, n. 4, p. 158-165, 2010.

DURLO, M. A.; DENARDI, L. Morfometria de Cabralea canjerana, em mata secundaria nativa do Rio Grande do Sul. Ciência Florestal, Santa Maria, v. 8, n. 1, p. 55-66, 1998.

- Morfometria de Cabralea canjerana, em mata secundaria nativa do Rio Grande do Sul. Ciência Florestal, Santa Maria, v. 8, n. 1, p. 55-66, 2009.

EMPRESA BRASILEIRA DE PESQUISA AGROPECUÁRIA EMBRAPA - EMBRAPA. Sistema brasileiro de classificação de solos. 2. ed. Rio de Janeiro: EMBRAPA, 2006. 306 p.

FAIRLESS, D. Biofuel: the little shrub that could-maybe. Nature, Londres, v. 449, n. 7163, p. 652-655, 2007.

GONÇALVES, J. L. M.; SANTARELLI, E. G.; MORAES NETO, S. P.; MANARA, M.P. Produção de mudas de espécies nativas:substrato, nutrição, sombreamento e fertilização. In: GONÇALVES, J. L. M.; BENEDETTI, V. (Ed.). Nutrição e fertilização florestal. Piracibaba: IPEF, 2005. p. 309-350.

LAVIOLA, B. G.; DIAS, L. A. S. Teor e acúmulo de nutrientes em folhas e frutos de pinhão-manso. Revista Brasileira de Ciência do Solo, Viçosa, v. 32, n. 5, p. 1969-1975, 2008.
LIMA, R. L. S. D.; SEVERINO, L. S.; PEREIRA, W. E.; LUCENA, A. M. A.; CHEYI, H. R.; ARRIEL, N. H. C. Comprimento das estacas e parte do ramo para formação de mudas de pinhão-manso. Revista Brasileira de Engenharia Agrícola e Ambiental, Campina Grande, v. 14, n. 11, p. 1234-1239, 2010.

LUCENA, A. M. A.; ARRIEL, N. H. C.; FREIRE, M. A. O.; ALBUQUERQUE, F. A.; ANDREADE, J. R.; BELTRÃO, E. M. Descrição do padrão de floração do pinhão-manso. CONGRESSO BRASILEIRO DE MAMONA, 4.; SIMPÓSIO INTERNACIONAL DE OLEAGINOSAS ENERGÉTICAS, 1., 2010, João Pessoa. Anais... Campina Grande: Embrapa Algodão, 2010. p. 1681-1688.

MATOS, A. T. D.; ABRAHÃO, S. S.; MONACO, P. A. V. L.; SARMENTO, A. P.; MATOS, M. P.. Capacidade extratora de plantas em sistemas alagados utilizados no tratamento de águas residuárias de laticínios. Revista Brasileira de Engenharia Agrícola e Ambiental, Campina Grande, v. 14, n. 12, p. 1311-1317, 2010.

NUTTO, L. Manejo do crescimento diamétrico de Araucaria angustifolia (Bert.) O. Ktze. baseado na árvore individual. Ciência Florestal, Santa Maria, v. 11, n. 2, p. 9-25, 2001.

NUTTO, L.; TONINI, H.; BORSOI, G. A.; MOSKOVICH, F. A.; SPATHELF, P. Utilização dos parâmetros da copa para avaliar o espaço vital em povoamentos de Pinus elliottii Engelm. Boletim de Pesquisa Florestal, Colombo, v. 42, p. 110-122, 2001.

OLIVEIRA, S. J. C.; BELTRÃO, N. E. D. M. Crescimento de pinhão manso (Jatropha curcas) em função da poda e da adubação química. Revista Brasileira de Oleaginosas e Fibrosas, Campina Grande, v. 14, p. 9-17, 2010.

RIBEIRO, A. C.; PAULO T. G. G.; ALVAREZ V., V. H. Recomendações para o uso de corretivos e fertilizantes em Minas Gerais. $5^{a}$ aproximação. Lavras: MG/ CFSEMG, 1999. 359 p.

ROMAN, M.; BRESSAN, D. A.; DURLO, M. A. Variáveis morfométricas e relações interdimensionais para Cordia trichotoma (Vell.) Arrab. ex Steud. Ciência Florestal, Santa Maria, v. 19, n. 4, p. 473-480, 2009.

SANTOS, P. M.; FIDELIS, R. R.; PEREIRA, J. C. S.; ERASMO, E. A. L.; BARROS, H. B.; CARVALHO, G. L. Formas e épocas de amostragem em folhas de pinhão manso para quantificação da área foliar. Journal of Biotechnology and Biodiversity, Tocantins, v. 2, n. 3, p. 51-57, 2011. 
SELLE, G. L.; SCHNEIDER, P. R.; FINGER, C. A. G. Classificacão de sítio para Pinus taeda L., através da altura dominante, para a região de Cambará do Sul, RS, Brasil. Ciência florestal, Santa Maria, v. 4, n. 1, p. 75-95, 1994.

SOARES, A. B.; SARTOR, L. R.; ADAMI, P. F.; VARELLA, A. C.; FONSECA, L.; MEZZALIRA, J. C. Influência da luminosidade no comportamento de onze espécies forrageiras perenes de verão. Revista Brasileira de Zootecnia, Viçosa, v. 38, n. 3, p. 443-451, 2009.
TOMÉ, M.; RIBEIRO, F.; FAIAS, S. Relação hipsométrica geral para Eucalyptus globulus Labill. em Portugal. Silva Lus, Lisboa, v. 15, n. 1, p. 41-55, 2007.

TONINI, H.; ARCO-VERDE, M. F. Morfologia da copa para avaliar o espaço vital de quatro espécies nativas da Amazônia. Pesquisa Agropecuária Brasileira, Brasília, v. 40, n. 7, p. 633-638, 2005. 